\title{
Asset pricing and systematic liquidity risk: An empirical investigation of the Spanish stock market
}

\author{
Miguel A. Martínez ${ }^{\mathrm{a}}$, Belén Nieto ${ }^{\mathrm{b}}$, Gonzalo Rubio ${ }^{\mathrm{a}, *}$, Mikel Tapia $^{\mathrm{c}}$ \\ ${ }^{a}$ Dipartimento de Fundamentos del Análisis Económico, Facultad de Ciencias Económicas, \\ Universidad del País Vasco, Avda. del Lehendakari Aguirre 83, 48015 Bilbao, Spain \\ ${ }^{\mathrm{b}}$ Universidad de Alicante, Spain \\ ${ }^{\mathrm{c}}$ Universidad Carlos III, Spain
}

Received 12 February 2003; received in revised form 24 October 2003; accepted 16 December 2003 Available online 19 March 2004

\begin{abstract}
Systematic liquidity shocks should affect the optimal behavior of agents in financial markets. Indeed, fluctuations in various measures of liquidity are significantly correlated across common stocks. Accordingly, this paper empirically analyzes whether Spanish average returns vary cross sectionally with betas estimated relative to three competing liquidity risk factors. The first one, proposed by Pastor and Stambaugh [J. Polit. Econ. III (2003) 642], is associated with the temporary price fluctuation reversals induced by the order flow. Our market-wide liquidity factor is defined as the difference between returns highly sensitive to changes in the relative bid-ask spread and returns with low sensitivities to those changes. Finally, the aggregate ratio of absolute stock returns to euro volume, as suggested by Amihud [J. Financ. Mark. 5 (2002) 31], is also employed. Our empirical results show that systematic liquidity risk is significantly priced in the Spanish stock market exclusively when betas are measured relative to the illiquidity risk factor based on the price response to one euro of trading volume on either unconditional or conditional versions of liquidity-based asset pricing models.
\end{abstract}

JEL classification: $\mathrm{G} 12$

Keywords: Systematic liquidity risk; Expected returns; Bid-ask spread; Order flow; Trading volume

\section{Introduction}

The key issue in asset pricing theory is the specific functional form of the stochastic discount factor. In particular, the relevant literature discusses whether the aggregate discount factor is linear or not in

\footnotetext{
* Corresponding author. Tel.: +34-946-013-770; fax: +34-946-013-774

E-mail address: jepruirg@bs.ehu.es (G. Rubio).
} 
alternative state variables, what the appropriate number and economic meaning of these competing variables might be, and what the relevance of idiosyncratic income shocks and incomplete markets might be. ${ }^{1}$

Rather surprisingly, at the same time, asset pricing generally does not deal with the actual mechanisms of the trading process and how those characteristics affect the price formation of financial assets. One important exception is the literature associated with the liquidity premium of infrequently traded stocks. ${ }^{2}$ Closely related is the recent work of Easley, Hvidkjaer, and O'Hara (2002), in which the authors study the role of information-based trading in affecting expected stock returns. They argue that stocks with a higher probability of being traded with private information require compensation in expected returns. They also point out that asymmetric information risk is, in some sense, systematic because traders cannot diversify away the probability of information-based trading simply because they do not know with whom they are trading. In any case, it is not clear how this idiosyncratic characteristic of a given stock might be embedded in the stochastic discount factor. This remains as a clear limitation of this literature.

Interestingly, starting with the papers by Chordia, Roll, and Subrahmanyam (2000), Hasbrouck and Seppi (2001), and Huberman and Halka (1999), commonality in liquidity seems to be well documented in the U.S. stock market. In other words, fluctuations in various measures of liquidity are significantly correlated across common stocks. The issue then becomes whether systematic (market-wide) liquidity is priced in the stock market or whether a liquidity risk factor enters the stochastic discount factor as an additional state variable. Indeed, it is reasonable to expect systematic liquidity shocks to affect the optimal behavior of agents, given that stocks tend to perform badly in recessions, which may, of course, be easily characterized by aggregate liquidity restrictions. Hence, we may expect higher return on stocks to be highly and positively sensitive to systematic adverse liquidity shocks. As discussed by Pastor and Stambaugh (2003; P\&S hereafter) and Acharya and Pedersen (2003), when investors face an economic recession, and their overall wealth decreases, they may be forced to liquidate some assets to pay for their purchases. Unfortunately, this is relatively more costly when liquidity is lower, particularly when wealth has dropped and marginal utility is higher. Assets whose returns diminish precisely at these time periods (with positive covariances relative to market-wide liquidity) will be required to offer extra expected returns. Moreover, these effects will be even more pronounced for assets that react strongly to changes in market-wide liquidity crises. Therefore, investors will require a systematic liquidity premium to hold such highly positively sensitive assets.

Aggregate arguments associated with liquidity restrictions directly related to the discussion above have been put forward by Acharya and Pedersen (2003), Amihud (2002), Domowitz and Wang (2002), Ericsson and Renault (2000), Holmström and Tirole (2001), Lustig (2001), P\&S (2003), and Sadka (2003). These papers develop either theoretical or empirical arguments implying a covariance between returns and some measure of aggregate liquidity. Their work may be understood as attempts to rationalize the consequences of commonality in liquidity and to justify the need for empirical research analyzing the impact of aggregate liquidity shocks on asset pricing.

Our paper is mostly related to P\&S (2003), who developed a measure of market-wide liquidity based on price reversals and tested whether assets that highly covary with their factor obtain higher average returns, and to Sadka (2003), who uses the estimated price impact to introduce a liquidity factor based on innovations to aggregate liquidity. Both papers suggest that liquidity risk is a factor priced in the market.

\footnotetext{
1 Recent surveys may be found in Campbell (2001), Cochrane (2001), and Constantinides (2002).

2 Classic examples are the papers by Amihud and Mendelson (1986) and Brennan and Subrahmanyam (1996).
} 
Along these lines, our empirical work analyzes whether the Spanish expected returns during the 1990s are associated cross sectionally with betas estimated relative to three competing liquidity risk factors. In particular, we propose a new market-wide liquidity factor that is defined as the difference between the returns of stocks highly sensitive to changes in the relative bid-ask spread and the returns from stocks with low sensitivities to those changes. We argue that stocks with positive covariability between returns and this factor are assets whose returns tend to go down when aggregate liquidity is low and, hence, do not hedge a potential liquidity crisis. Consequently, investors will require a premium to hold these assets. ${ }^{3}$ On the other hand P\&S (2003), as mentioned above, suggest that a reasonable liquidity risk factor should be associated with the strength of volume-related return reversals because order flow induces greater return reversals when liquidity is lower. They show that their aggregate measure seems to be priced in the U.S. market and that the average risk-adjusted return on stocks highly sensitive to liquidity exceeds that for stocks with low sensitivity by $7.5 \%$ on an annual basis. Our empirical results show that neither of these proxies for systematic liquidity risk carries a premium in the Spanish stock market. Finally, Amihud (2002) proposes a simple, but intuitive, measure of stock illiquidity. In particular, illiquidity is defined for each individual stock as the ratio of the daily absolute return to the euro trading volume on that day. Then, and for each month in the sample period, this measure is averaged out across days and stocks to obtain an aggregate measure of illiquidity. Interestingly, both in time series and in the traditional cross-sectional framework, we find evidence consistent with market-wide liquidity risk being priced. Therefore, given an adequate illiquidity risk factor, it seems that the stochastic discount factor should be linearly related not only to the aggregate wealth return and state variables predicting future returns, but also to aggregate illiquidity risk.

It should be pointed out that besides the recent and relatively scant evidence from the U.S. market, to the best of our knowledge, there is no evidence regarding the importance of illiquidity as a risk factor in any other country. Thus, it is important to report empirical results from other data sets to check the robustness of the available results. Moreover, this is the first paper that simultaneously analyzes competing market-wide liquidity factors. Of course, it must be recognized that our sample period is short in comparison with the available evidence on asset pricing. This is not a problem in itself, but the results should be taken as valid just for the period being studied, and more general conclusions should be left for future research, when longer series of data will be readily available. In any case, it is important to mention that previous research for the Spanish stock market tends to show quite similar results with those traditionally reported for the U.S. market. In particular, Rubio $(1988,1995)$ shows that the standard CAPM (both with the equally and value-weighted market returns) and the APT with statistical factors are rejected. The well-known anomalies, such as size and January effects, book to market, and momentum, are also reported by Nieto and Rodríguez (2002), Forner and Marhuenda (2003) and Rubio (1988, 1990) respectively. As in other markets, the paper by Nieto and Rodríguez (2002, 2003) shows that dynamic asset pricing models, such as the conditional CAPM and alternative versions of intertemporal pricing models, perform better than do the static models including the static Fama and French (1993) threefactor model. Moreover, the temporal and cross-sectional behavior of bid-ask spreads and other measures of liquidity are also quite similar with results shown for the U.S. market. The papers by

\footnotetext{
3 Similarly, note that in the case of assets that covary negatively with the liquidity factor, investors may be willing to pay a premium rather than require additional compensation.
} 
Martínez, Rubio, and Tapia (2003) and Rubio and Tapia (1996) are relevant examples on these issues. We may therefore conclude that the favorable evidence on market-wide illiquidity reported in this paper is clearly informative for our further understanding of the behavior of asset prices.

The rest of the paper is organized as follows. Section 2 briefly describes the data used in this work. Section 3 reports additional evidence on commonality and discusses our liquidity risk factor, on the one hand, and both the market-wide measure proposed by P\&S (2003) and the aggregate illiquidity measure of Amihud (2002) on the other. Other results regarding general characteristics of the portfolios employed in our research are also reported. Section 4 contains the empirical results on asset pricing with marketwide liquidity risk factors, and Section 5 concludes.

\section{Data}

We have individual daily and monthly returns for all stocks traded on the Spanish continuous market from January 1991 through December 2000. The return of the market is an equally weighted portfolio comprised of all stocks available either in a given month or on a particular day in the sample. ${ }^{4}$ The monthly Treasury bill rate observed in the secondary market is used as the risk-free rate when monthly data are needed. All individual stocks are employed to construct three alternative liquidity-based 10 sorted portfolios, ${ }^{5}$ and also the traditional 10 portfolios formed according to market value. Data from portfolios are always monthly returns. For the same set of common stocks, we also have daily data on the relative bid-ask spread, depth, and both the number of shares traded and the euro trading volume.

Moreover, two additional variables have been used to construct risk factors in different asset pricing models. In particular, for the Fama-French unconditional three-factor model, we employ a size proxy and the book-to-market ratio (BM). As a measure of size for each company in a single month, we use the logarithm of market value, calculated by multiplying the number of shares of each firm in December of the previous year by their price at the end of each month. To compute the BM ratio for each firm, we employ the accounting information from the balance sheets of each firm at the end of each year. For the years as from 1990, this information is provided by the National Security Exchange Commission. The book value for any firm in month $t$ is given by its value at the end of the previous year, and it remains constant from January to December. The market value is given by the total capitalization of each company in the previous month. These data are employed to construct the well-known SMB and HML Fama-French portfolios, as is commonly done in literature. For the conditional asset pricing models used in the paper, we propose the aggregate BM ratio as the relevant state variable, calculated as the arithmetic mean of the individual BM ratios. Nieto (2002) and Nieto and Rodríguez (2002) show that the aggregate BM is a good predictor of future market returns and, for Spanish data, seems to be superior to the deviations (from the long-run equilibrium level) of the consumption to wealth ratio proposed by Lettau and Ludvigson (2001).

\footnotetext{
4 The official Stock Exchange value-weighted index is also employed to check the robustness of some of the empirical results shown later in the paper.

5 These are described in the next section.
} 


\section{Commonality and systematic liquidity}

\subsection{Brief evidence on commonality in liquidity}

Our discussion in the previous section suggests that asset pricing and liquidity have not been properly addressed in the standard literature. We should not regress common stock returns on individual characteristics of liquidity, such as the relative bid-ask spread, adverse selection, depth, or probability of information-based trading, but rather on a proxy for a liquidity factor reflecting aggregate (marketwide) liquidity restrictions.

To confirm that there exists commonality in liquidity in the Spanish stock market, we regress the monthly percentage change in the relative bid-ask spread for each of the 204 companies available in the sample, $\mathrm{DSP}_{j t}$, on a cross-sectional, equally weighted average of the same variable representing the market-wide relative spread, $\mathrm{DSP}_{\mathrm{m} t}$,

$$
\mathrm{DSP}_{j t}=\alpha_{j}+\beta_{j} \mathrm{DSP}_{\mathrm{m} t}+\varepsilon_{j t} .
$$

The cross-sectional average of the 204 individual coefficients is reported in Table 1 . The average sensitivity of changes in the bid-ask spread relative to changes in the aggregate measure of liquidity is a significant 0.88 . Moreover, most of the individual coefficients are positive and significantly different from zero. This indicates that individual liquidity comoves with market liquidity and that commonality in liquidity exists in the Spanish market.

\subsection{Liquidity risk factors}

\subsubsection{The Pastor and Stambaugh factor (OFL)}

The market-wide liquidity factor proposed by P\&S (2003) in a given month is obtained as the equally weighted average of the liquidity measures of individual stocks, which are calculated with daily return and volume data within that particular month. Hence, for a given month $t$ and a security $j$, we perform the following OLS regression using daily data, as long as the stock has at least 15 observations in that month:

$$
R_{j d+1 t}^{e}=a_{j t}+b_{j t} R_{j d t}+\lambda_{j t} \operatorname{sign}\left(R_{j d t}^{e}\right) \operatorname{vol}_{j d t}+u_{j d+1 t}
$$

where $R_{j d+1 t}^{e}$ is the return on stock $j$ on day $d+1$ (in month $t$ ) minus the market return on the same day, $R_{j d t}$ is the return on stock $j$ on day $d$, and $\operatorname{vol}_{j d t}$ is the euro volume for stock $j$ on day $d$ in month $t$. The key

Table 1

Market-wide commonality in liquidity 1991-2000

\begin{tabular}{lcccc}
\hline & Average alpha & Average beta & Average $R^{2}$ & Average adjusted $R^{2}$ \\
\hline Coefficient (average $t$ statistic) & $.0886(1.031)$ & $.8815(2.639)$ & .1377 & .1091 \\
$\%$ Positive & - & 94.1 & - & - \\
$\%+$ Significant & - & 63.2 & - & - \\
\hline
\end{tabular}

$$
\operatorname{DSP}_{j t}=\alpha_{j}+\beta_{j} \mathrm{DSP}_{\mathrm{m} t}+\varepsilon_{j t}
$$

where $\mathrm{DSP}_{j t}$ is the percentage change from month $t-1$ to $t$ in liquidity, as proxied by the relative spread of stock $j$, and DSP $t$ is the concurrent change in a cross-sectional average of the same variable or the market-wide (equally weighted) relative spread. Average numbers reported are for 204 stocks. 
coefficient is the sensitivity of the percentage price change of stock $j$ on day $t+1$ to the order flow on $t$, constructed as the volume signed by the returns on the stock minus the return on the market. The basic idea behind the model is that a financial market may be considered liquid if it is able to quickly absorb large amounts of trading without distorting prices. In other words, when a big change in the price of a stock is needed to accommodate its demand, the asset is considered to be illiquid. If there is selling (buying) pressure on asset $j$ by noninformational investors, relative to the aggregate market, the price and return (again with respect to the market) go down (up), and the expected return for the next period increases (decreases). In other words, order flow (signed volume in the above regression) should be associated with a return that we expect to be reversed in the future if the asset is not sufficiently liquid. We therefore expect $\lambda_{j t}$ to be negative and larger in absolute value when liquidity decreases. The greater the order flow the greater the change in the expected return will be.

The relevant variable should rather be changes in sensitivities to market-wide liquidity and, therefore, we first aggregate over assets to obtain $\hat{\lambda}_{t}=1 / N_{t} \sum_{j=1}^{N_{t}} \hat{\lambda}_{j t}$, and then, we take differences,

$$
\Delta \hat{\lambda}_{t}=\left(\frac{m_{t}}{m_{1}}\right) \frac{1}{N_{t}} \sum_{j=1}^{N_{t}}\left(\hat{\lambda}_{j t}-\hat{\lambda}_{j t-1}\right)
$$

where, $m_{t}$ is the total euro value at the end of month $t$ of the stocks included in the IBEX-35 index, Month 1 corresponds to December 1990, and $N_{t}$ is the number of available stocks in month $t$. We obtain this measure using our 204 stocks from January 1991 to December 2000. ${ }^{6}$ Moreover, the variable is adjusted by the magnitude of the market, and, finally, innovations in the adjusted measure are employed as the market-wide liquidity factor. In particular, the liquidity factor is given by the residuals in the following expression:

$$
\Delta \hat{\lambda}_{t}=c+d \Delta \hat{\lambda}_{t-1}+e\left(\frac{m_{t-1}}{m_{1}}\right) \hat{\lambda}_{t-1}+\varepsilon_{t} .
$$

The final systematic liquidity factor is taken as the fitted residual of Eq. (4), scaled by $10^{9}$, simply to obtain more convenient magnitudes of the liquidity market-wide factor: ${ }^{7}$

$$
\mathrm{OFL}_{t}=\hat{\varepsilon}_{t} \times 10^{9}
$$

Stocks that covary positively with OFL have a large liquidity risk, and investors will demand a higher return from them. Hence, we expect a positive premium associated with this risk factor in asset pricing models.

\subsubsection{The illiquidity factor (ILLQ)}

The idea behind this measure is to capture, in a very simple but intuitive way, the price impact as the response associated with one euro of trading volume. In particular, Amihud (2002) proposes measuring

\footnotetext{
${ }^{6}$ Not all stocks are available throughout the period.

7 The scale factor is different from P\&S (2003), given that volume is measured in euros, while in the case of P\&S, it is in millions of dollars.
} 
illiquidity for a given stock on a given day as the ratio of absolute percentage price change per euro of daily trading volume. Of course, this resembles Kyle's lambda as given by the response of price to order flow. Thus, the illiquidity of stock $j$ in month $t$ is given by

$$
\operatorname{ILLQ}_{j t}=\frac{1}{D_{j t}} \sum_{d=1}^{D_{j t}} \frac{\left|R_{j d t}\right|}{V_{j d t}}
$$

where $R_{j d t}$ and $V_{j d t}$ are, respectively, the return and euro volume on day $d$ in month $t$, and $D_{j t}$ is the number of days with observations in month $t$ of stock $j$. When a particular stock has a high value of $\mathrm{ILLQ}_{j t}$, it indicates that the price moves quite a lot in response to trading volume and, therefore, the stock is considered to be illiquid. It is important to point out that Hasbrouck (2002) finds that this measure appears to be the best among the usual proxies employed to capture Kyle's lambda. To obtain the market-wide liquidity risk factor, we simply aggregate this measure across stocks in the following manner: ${ }^{8}$

$$
\mathrm{ILLQ}_{t}=\frac{1}{N_{t}} \sum_{j=1}^{N_{t}} \mathrm{ILLQ}_{j t}
$$

where, as before, $N_{t}$ is the number of stocks available in month $t$ in our sample.

When this factor increases, we may understand that there is an adverse shock to aggregate liquidity. Stocks that tend to pay lower returns when this measure increases (negative betas relative to this factor) do not provide the desirable hedging behaviour to investors, and, therefore, an extra compensation is required to hold these stocks. This implies that the premium associated to this liquidity factor in a crosssection should be negative.

\subsubsection{The bid-ask spread-return factor (HLS)}

The basic idea behind this factor is to form a portfolio as the difference between the returns on a long position on assets especially sensitive to changes in the relative bid-ask spread and a short position on assets with the lowest sensitivity. This is similar in spirit with the Fama-French factors and to the market risk factor, understood as the difference between the return on the risky assets (the market portfolio) and the risk-free rate.

In particular, we estimate how sensitive each asset is to variations in relative spread in the sample: ${ }^{9}$

$$
R_{j t}=a_{j}+b_{j} \mathrm{DSP}_{j t}+u_{j t}
$$

Assets are classified in three blocks according to their sensitivities: high, medium, and low sensitivity to spread variations. This ranking is changed every month according to their sensitivities over the previous 36 months in the sample. For each block (and each month), equally weighted portfolios are formed using the assets that belong to each block. We have monthly time-series of three equally weighted

\footnotetext{
8 Throughout the paper, this measure is multiplied by a scale factor of $10^{8}$.

9 Similar results are obtained when we regress on changes in the average market-wide bid-ask spread. The empirical results reported in the paper are all based on Eq. (8).
} 
portfolios (HS, MS, LS) between January 1992 and December 2000. The liquidity factor is defined as the difference between the returns of the high- and the low-sensitivity portfolio returns: HLS=HS-LS.

The intuition behind our proposal is the existing negative covariance between market returns and credit (liquidity) restrictions. The 1929 and 1987 crashes, the Russian debt crisis and its effects on the Long-term Capital Management hedge fund, the recent Asian financial crisis, or the strong negative shock on liquidity on September 11th are all excellent examples. It is always the case that the larger the restriction in liquidity, the lower the market return is. At the same time, the covariance between the changes in the average aggregate bid-ask spread and the market return is negative. ${ }^{10}$ Both results imply a positive covariance between liquidity restrictions and changes in the bid-ask spread, both aggregately and individually. ${ }^{11}$ This reasoning justifies our classification of assets according to the slope coefficient of Eq. (8) to construct our systematic liquidity factor. Accordingly, the relevant covariance for analyzing the sensitivity between returns and liquidity shocks is the covariance between stock returns and changes in the bid-ask spread.

It is important to note that assets with low sensitivity to changes in the bid-ask spread (LS) are those whose returns diminish relatively little when the change in the bid-ask spread increases. On the other hand, highly sensitive stocks (HS) tend to have returns that go down by a relatively large amount when the spread increases. ${ }^{12}$ This implies that the portfolio returns of assets with high sensitivity minus low sensitivity, our HLS factor, must necessarily go down when changes in the spread increase (less liquidity in the market as a whole). Hence, negative liquidity shocks imply that the returns associated with our systematic liquidity factor will tend to go down. Thus, stocks with positive covariances between their returns and the HLS factor are assets whose returns tend to decrease when market-wide liquidity is lower. These assets are not able to hedge negative liquidity shocks, and investors will require an additional premium to hold them. On average, we would expect a positive relationship between average returns and liquidity betas relative to our factor.

\subsection{Some preliminary empirical evidence}

We first calculate the usual descriptive statistics of the factors employed in this research. Table 2 reports the average characteristics of the distribution of the market return factor, the Fama-French factors, and the three liquidity-based systematic factors. The latter present rather large excess kurtosis, at least relative to the other factors, and both the OFL and HLS market-wide measures have left-skewed distributions. Interestingly, the OFL and ILLQ factors are much more volatile than the HLS market-wide measure is. The correlation coefficients between them all tend to be low, although ILLQ has a relatively high positive correlation of .32 with the HML factor proposed by Fama-French. This is an interesting result as, if we understand the HML factor as a recession risk factor, then, it seems reasonable to expect a high and positive correlation between them. Moreover, as expected, the market return is more positively correlated with HLS than with OFL, and negatively related to ILLQ. Finally, it should be pointed out that although it is clearly small, the positive correlation between OFL and ILLQ is disturbing. Given the way that these two factors are constructed, and assuming that they correctly capture market-wide liquidity, we

10 The correlation coefficient between these variables, over the $1990 \mathrm{~s}$, turned out to be -.348 .

11 In fact, the correlation coefficient between the changes in the risk-free rate and the spread over our sample period was .157 .

12 The slope coefficient in Eq. (8) is negative in all cases. 
Table 2

Summary statistics for risk factors $1993-2000$

\begin{tabular}{|c|c|c|c|c|c|c|}
\hline \multicolumn{5}{|l|}{ (A) } & & \\
\hline Risk factor & Average return & Volatility & Skewness & Excess kurtosis & & \\
\hline RM & 19.53 & 18.75 & 0.765 & 1.242 & & \\
\hline SMB & -0.69 & 13.15 & 0.656 & 0.224 & & \\
\hline HML & 1.48 & 11.00 & 0.493 & 0.140 & & \\
\hline HLS & -0.04 & 12.38 & -1.009 & 6.043 & & \\
\hline OFL & -1.17 & 25.20 & -1.389 & 4.122 & & \\
\hline ILLQ & 1.67 & 18.56 & 1.867 & 4.140 & & \\
\hline \multicolumn{7}{|c|}{ (B) Correlation coefficients } \\
\hline & $\mathrm{RM}$ & SMB & HML & HLS & $\mathrm{OFL}$ & ILLQ \\
\hline RM & 1.000 & 0.066 & -0.097 & 0.160 & 0.069 & -0.089 \\
\hline SMB & & 1.000 & 0.094 & 0.139 & 0.218 & 0.111 \\
\hline HML & & & 1.000 & -0.042 & 0.094 & 0.316 \\
\hline HLS & & & & 1.000 & 0.067 & 0.020 \\
\hline OFL & & & & & 1.000 & 0.188 \\
\hline ILLQ & & & & & & 1.000 \\
\hline
\end{tabular}

The numbers represent the average annualized average returns, volatilities, skewness, excess kurtosis and correlation coefficients of alternative risk factors employed in the paper. RM is the equally weighted market portfolio, SMB is the FamaFrench size-related factor, HML is the Fama-French BM-related factor, HLS is the liquidity factors associated with sensitivities to the bid-ask spread, OFL is the liquidity factor based on the order flow, inducing greater return reversals when liquidity is lower, and ILLQ is the monthly average across days and stocks of the ratio of absolute stock return to euro volume (multiplied by $10^{8}$ ). The figures are obtained from monthly returns from January 1993 to December 2000.

should expect a negative correlation. Fig. 1 plots the HLS, OFL, and ILLQ factors. Note the large volatility impounded in the OFL and ILLQ systematic liquidity measures. ${ }^{13}$

We construct 10 size-sorted portfolios according to the market value of each security at the end of each year, named MV1 (smallest) to MV10 (largest), and 10 liquidity-based sorted portfolios, ranking stocks with respect to the liquidity betas that they have in terms of the three liquidity factors employed in this paper. These betas are estimated with 36 past observations, and stocks are assigned to a given portfolio at the end of every month in the sample on the basis of the estimated beta coefficient. ${ }^{14}$ The average return and volatility of these portfolios are shown in Table 3. These are the portfolio returns that will be employed in testing the liquidity-based asset pricing models in the next section. As expected, the smallest stocks have the largest volatility, and there is also a tendency towards lower volatility the larger the stocks included in the portfolios. The volatility of the OFL and HLS liquidity-based portfolios is higher in the extreme ones. Stocks both highly positively and negatively sensitive to changes in the bid-ask spread tend to have the largest volatility. This is in itself an interesting finding that deserves further attention. In terms of average returns, the volatility pattern is reproduced for the HLS portfolios but not for the OFL classification. In fact, contrary to the findings of P\&S (2003), OFL1 (highly negatively sensitive stocks) have a much larger average return than OFL10 (highly positively sensitive stocks) does. The liquiditybased betas follow precisely the pattern expected given the ranking of the individual stocks, although they

\footnotetext{
13 Note, on the other hand, that the volatility of replicating factors such as SMB, HML, or HLS, is always relatively low, given the way that these factors are constructed as portfolios of long versus short positions on financial assets.

14 The month in which we classify stocks is also included in the estimation of the liquidity betas.
} 


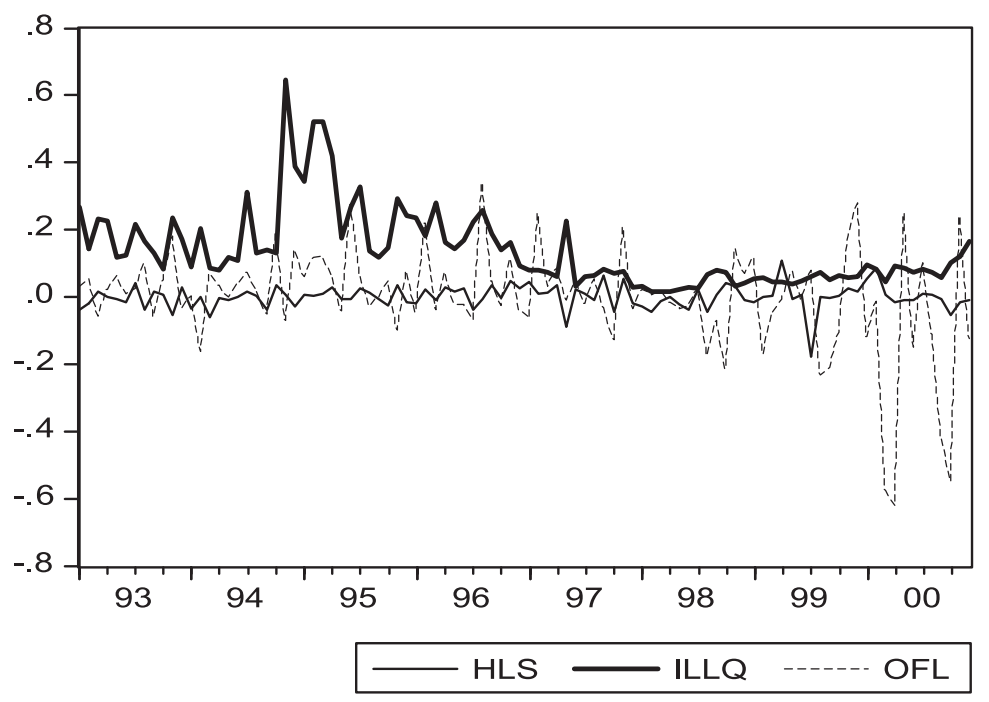

Fig. 1. Aggregate liquidity factors.

seem to be estimated with much more precision when the HLS factor is used in the estimation. Finally, large stocks have a relatively high and significant HLS beta but much lower OFL betas.

The most striking characteristic of Table 3 is the results associated with the portfolios constructed on the basis of ILLQ. Particularly relevant is the extremely large difference in average returns between ILLQ1 and ILLQ10. Moreover, there is an almost perfect monotonic relation between the sensitivity of returns to the ILLQ factor and average returns. This seems to suggest that the ILLQ is indeed a reasonable market-wide liquidity factor. Stocks highly negatively sensitive to ILLQ have a much larger average return than do highly positively sensitive stocks. The same pattern is found in terms of risk measures. Volatility also presents an almost perfect monotonic relation. ${ }^{15}$ ILLQ1 assets have a much larger risk than ILLQ10 securities do. At the same time, the only significant liquidity betas correspond to the extreme portfolios. ILLQ1 stocks tend to move down when there is a market-wide liquidity adverse shock, while ILLQ10 tend to covary in the opposite way. This implies that stocks that belong to ILLQ10 provide a hedging opportunity to investors. It should be pointed out that the stocks in this portfolio are not always the blue chips of the Spanish Stock Exchange. It is definitely striking that ranking stocks according to this liquidity beta produces such a clear pattern of average return and risk.

To confirm the commonality of liquidity reported with individual stocks in Table 1, we perform a similar regression with our 10 size- and liquidity-based sorted portfolios. The results are shown in Table 4. We expect the slope of Eq. (1) to be positive and significant for all portfolios, and, indeed, this is the case in most cases. At the same time, however, there are differences between the alternative sets of portfolios. For example, for the HLS portfolios, we observe that the relative spread of negatively sensitive portfolios changes more with market-wide spread than positively sensitive portfolios. ${ }^{16}$ This

15 The same pattern is found in market betas, although the results are not shown in Table 3. The market beta of ILLQ1 is 1.31, while the corresponding beta for ILLQ10 is 0.72 .

16 The average slope coefficient for the first five portfolios is 1.489 , while for the last five portfolios, it is only 0.584 . 
Table 3

Summary statistics for portfolios 1993-2000

\begin{tabular}{|c|c|c|c|c|c|}
\hline Portfolios & Average return & Volatility & HLS beta ( $t$ statistic) & OFL beta ( $t$ statistic) & ILLQ beta ( $t$ statistic) \\
\hline HLS1 & 20.84 & 26.43 & $-0.583(-2.75)$ & - & - \\
\hline HLS2 & 17.14 & 19.85 & $-0.074(-0.45)$ & - & - \\
\hline HLS4 & 14.00 & 15.97 & $0.049(0.40)$ & - & - \\
\hline HLS5 & 17.23 & 19.19 & $0.117(0.73)$ & - & - \\
\hline HLS6 & 15.72 & 18.78 & $0.219(1.41)$ & - & - \\
\hline HLS8 & 19.06 & 21.16 & $0.446(2.56)$ & - & - \\
\hline HLS9 & 16.62 & 21.07 & $0.606(3.70)$ & - & - \\
\hline HLS10 & 21.77 & 26.60 & $0.855(4.21)$ & - & - \\
\hline OFL1 & 27.13 & 25.07 & - & $-0.067(-1.45)$ & - \\
\hline OFL2 & 20.57 & 18.71 & - & $-0.022(-0.63)$ & - \\
\hline OFL6 & 12.49 & 16.66 & - & $0.017(0.57)$ & - \\
\hline OFL7 & 18.38 & 21.65 & - & $0.030(0.73)$ & - \\
\hline OFL8 & 15.92 & 20.69 & - & $0.043(1.12)$ & - \\
\hline OFL9 & 23.45 & 21.92 & - & $0.042(1.03)$ & - \\
\hline OFL10 & 13.93 & 24.03 & - & $0.093(2.12)$ & - \\
\hline ILLQ1 & 30.62 & 28.61 & - & - & $-0.172(-2.46)$ \\
\hline ILLQ2 & 25.80 & 25.62 & - & - & $-0.114(-1.78)$ \\
\hline ILLQ3 & 20.10 & 25.45 & - & - & $-0.107(-1.67)$ \\
\hline ILLQ4 & 20.96 & 21.35 & - & - & $-0.060(-1.11)$ \\
\hline ILLQ5 & 19.41 & 22.52 & - & - & $-0.020(-0.35)$ \\
\hline MV3 & 12.81 & 21.11 & $0.299(1.72)$ & $0.002(0.06)$ & $-0.037(-0.70)$ \\
\hline MV4 & 18.75 & 21.88 & $0.097(0.53)$ & $0.012(0.28)$ & $-0.055(-0.99)$ \\
\hline MV5 & 20.45 & 18.69 & $0.231(1.50)$ & $0.033(0.94)$ & $-0.032(-0.67)$ \\
\hline MV6 & 15.20 & 17.91 & $0.180(1.21)$ & $0.005(0.14)$ & $-0.032(-0.71)$ \\
\hline MV7 & 17.59 & 16.64 & $0.146(1.06)$ & $0.019(0.61)$ & $-0.023(-0.55)$ \\
\hline MV8 & 19.77 & 17.91 & $0.320(2.20)$ & $0.020(0.59)$ & $0.009(0.19)$ \\
\hline MV9 & 20.30 & 18.46 & $0.362(2.43)$ & $0.034(1.00)$ & $-0.023(-0.47)$ \\
\hline MV10 & 19.78 & 19.33 & $0.523(3.45)$ & $0.063(1.78)$ & $-0.016(-0.32)$ \\
\hline
\end{tabular}

The summary statistics represent the time-series-annualized averages of returns, volatilities, and factor betas of four differently sorted portfolios according to: (i) the sensitivities of returns with changes in the relative bid-ask spread (HLS); (ii) the sensitivities of returns to fluctuations in aggregate liquidity, as measured by order flow inducing greater return reversals when liquidity is lower (OFL); (iii) the sensitivity of returns to the monthly average across days of the absolute percentage price change per euro of trading volume (ILLQ); and (iv) market capitalization (MV). HLS1 and OFL1 represent stocks negatively sensitive to market-wide liquidity, ILLQ1 includes stocks negatively sensitive to market-wide illiquidity, and MV1 has small market value stocks. Data are from January 1993 to December 2000. 
Table 4

Market-wide commonality in liquidity (relative spread) portfolios by aggregate liquidity and market value $1993-2000$

\begin{tabular}{|c|c|c|c|}
\hline Portfolios & Slope coefficient & $t$ Statistic & Adjusted $R^{2}$ \\
\hline HLS1 & 1.899 & $(7.30)$ & .357 \\
\hline HLS2 & 1.434 & (1.98) & .090 \\
\hline HLS3 & 1.004 & $(4.45)$ & .167 \\
\hline HLS4 & 1.620 & $(5.11)$ & .211 \\
\hline HLS5 & 1.489 & $(4.04)$ & .140 \\
\hline HLS6 & 0.839 & $(2.38)$ & .047 \\
\hline HLS7 & 0.552 & $(1.21)$ & .050 \\
\hline HLS8 & 0.669 & $(4.20)$ & .150 \\
\hline HLS9 & 0.328 & (1.98) & .030 \\
\hline HLS10 & 0.530 & $(5.59)$ & .243 \\
\hline OFL1 & 0.879 & $(3.99)$ & .137 \\
\hline OFL2 & 1.034 & $(5.98)$ & .270 \\
\hline OFL3 & 1.296 & $(4.71)$ & .184 \\
\hline OFL4 & 1.349 & $(3.50)$ & .107 \\
\hline OFL5 & 0.660 & $(2.25)$ & .042 \\
\hline OFL6 & 0.736 & $(1.98)$ & .030 \\
\hline OFL7 & 0.744 & $(3.56)$ & .120 \\
\hline OFL8 & 0.434 & $(2.10)$ & .035 \\
\hline OFL9 & 0.929 & $(4.65)$ & .180 \\
\hline OFL10 & 0.765 & $(5.00)$ & .203 \\
\hline ILLQ1 & 0.622 & (3.67) & .117 \\
\hline ILLQ2 & 1.119 & $(4.23)$ & .152 \\
\hline ILLQ3 & 1.040 & $(4.76)$ & .187 \\
\hline ILLQ4 & 1.330 & $(5.22)$ & .218 \\
\hline ILLQ5 & 1.226 & $(5.05)$ & .207 \\
\hline ILLQ6 & 0.382 & (1.91) & .027 \\
\hline ILLQ7 & 0.142 & $(0.64)$ & .006 \\
\hline ILLQ8 & 1.170 & $(5.45)$ & .234 \\
\hline ILLQ9 & 0.938 & $(2.07)$ & .034 \\
\hline ILLQ10 & 0.783 & $(3.47)$ & .106 \\
\hline MV1 & 1.266 & $(5.61)$ & .245 \\
\hline MV2 & 1.001 & $(5.55)$ & .241 \\
\hline MV3 & 0.915 & $(3.15)$ & .087 \\
\hline MV4 & 1.401 & $(3.62)$ & .114 \\
\hline MV5 & 1.119 & $(6.22)$ & .286 \\
\hline MV6 & 0.896 & (5.54) & .240 \\
\hline MV7 & 1.269 & $(6.33)$ & .294 \\
\hline MV8 & 0.595 & $(7.65)$ & .379 \\
\hline MV9 & 0.235 & $(2.30)$ & .044 \\
\hline MV10 & 0.100 & $(5.52)$ & .239 \\
\hline
\end{tabular}

$$
\mathrm{DSP}_{j t}=\alpha_{j}+\beta_{j} \mathrm{DSP}_{\mathrm{m} t}+\varepsilon_{j t}
$$

where $\operatorname{DSP}_{j t}$ is the percentage change from month $t-1$ to $t$ in liquidity, as proxied by the relative spread of portfolio $j$, and $\mathrm{DSP}_{\mathrm{m} t}$ is the concurrent change in a cross-sectional average of the same variable or the market-wide (equally weighted) relative spread. This table reports results from four differently sorted portfolios according to (i) the sensitivities of returns with changes in the relative bid-ask spread (HLS); (ii) the sensitivities of returns to fluctuations in aggregate liquidity, as measured by order flow inducing greater return reversals when liquidity is lower (OFL); (iii) the sensitivity of returns to the monthly average across days of the absolute percentage price change per euro of trading volume (ILLQ); and (iv) market capitalization (MV). HLS1 and 
result makes sense given that the factor employed to sort stocks between portfolios is based precisely on changes in individual spreads. Although less clearly defined, a similar result is found for OFL portfolios, which suggests that, at least in some sense, both liquidity-wide factors tend to measure similarly adverse liquidity events. Even more relevant are the large $t$ statistics associated with the slope coefficients for the extreme portfolios in both the HLS and OFL sensitivity-sorted stocks. It should be noted that these results are consistent with the findings reported in Table 3 . In absolute terms, these extreme portfolios are more sensitive to changes in the corresponding liquidity-wide factor.

On the other hand, in the case of ILLQ portfolios, we do not observe a well-defined pattern of the slope coefficient across portfolios. This may suggest that this factor does not contain the same liquidity related information as the relative spread and that these portfolios might be more appropriate for performing asset pricing model tests than other rankings. This corroborates, to some extent, the findings of Table 3 in terms of the increasing and highly disperses structure of average returns and volatility.

\section{Asset pricing and systematic liquidity: the empirical evidence}

\subsection{Alphas and asset pricing models}

One way of testing the asset pricing models described in this paper is to note that if the liquidity risk factors are priced in the market, we should find systematic differences in the market risk-adjusted average returns of our liquidity-beta-sorted portfolios. In other words, for a given asset pricing model, the risk-adjusted average return (alpha) of the HLS10 portfolio should be significantly higher than the alpha for the HLS1 portfolio. The same results should be observed for the OFL liquidity portfolios as long as the market prices market-wide liquidity risk. On the other hand, given the way in which ILLQ is defined, the opposite results should hold. If there is a significant liquidity premium associated with aggregate liquidity risk, the difference in average market risk-adjusted returns between ILLQ10 and ILLQ1 should be significantly negative. This is the approach followed by P\&S (2003) to test alternative asset pricing models. They find that average risk-adjusted returns of stocks with high sensitivity to liquidity exceed those for stocks with low sensitivity by $7.5 \%$ on an annual basis when a four-factor asset pricing model is employed in the estimation. ${ }^{17}$ Indeed, $\mathrm{P} \& \mathrm{~S}$ interpret the result as the average liquidity premium existing in the U.S. market between 1966 and 1999.

As reported in Table 5, when we follow the same testing strategy, our results are dramatically different from those reported by P\&S (2003) for both the HLS and OFL liquidity factors. The liquidity risk premium only exists for ILLQ. We employ five alternative pricing models: the traditional CAPM, the three-factor Fama-French model, and the three CAPM liquidity-based models discussed in this paper, in which we add the liquidity factor (either HLS, OFL, or ILLQ) to the standard CAPM model. We report the differences in alphas between January 1993 and December 2000 on an annual basis.

\footnotetext{
17 The three Fama-French factors plus a momentum factor. In any case, regardless of which model is used, they find very similar evidence.
} 
Table 5

Differences between alphas of extreme portfolios sorted on aggregate liquidity and market value 1993-2000

(A) Liquidity-sorted portfolios

\begin{tabular}{|c|c|c|c|c|c|c|c|c|c|}
\hline & \multicolumn{3}{|c|}{ Alpha HLS10-alpha HLS1 } & \multicolumn{3}{|c|}{ Alpha OFL10-alpha OFL1 } & \multicolumn{3}{|c|}{ Alpha ILLQ10-alpha ILLQ1 } \\
\hline & Value $^{\mathrm{a}}$ & $\chi^{2}$ Test $^{b}$ & $P$ value & Value & $\chi^{2}$ Test & $P$ value & Value & $\chi^{2}$ Test & $P$ value \\
\hline CAPM alpha & -1.78 & 0.048 & .826 & -13.86 & 4.425 & .035 & -12.32 & 4.450 & .035 \\
\hline Fama-French alpha & -1.14 & 0.020 & .889 & -13.40 & 4.086 & .043 & -12.96 & 5.177 & .023 \\
\hline CAPM+HLS alpha & -0.02 & 0.000 & .998 & -13.59 & 4.274 & .039 & -12.24 & 4.352 & .034 \\
\hline CAPM+OFL alpha & -1.74 & 0.045 & .831 & -13.37 & 4.627 & .032 & -12.39 & 4.479 & .034 \\
\hline CAPM+ILLQ alpha & -17.14 & 1.832 & .176 & -28.72 & 7.827 & .005 & -54.20 & 42.982 & .000 \\
\hline
\end{tabular}

\begin{tabular}{lcll}
\hline & \multicolumn{3}{c}{ Alpha MV10-alpha MV1 } \\
\cline { 2 - 4 } & Value $^{\mathrm{a}}$ & $\chi^{2}$ Test $^{\mathrm{b}}$ & $P$ value \\
\hline CAPM alpha & 0.30 & 0.002 & .968 \\
Fama-French alpha & 0.86 & 0.015 & .903 \\
CAPM+HLS alpha & 1.06 & 0.022 & .88 \\
CAPM+OFL alpha & 0.45 & 0.004 & .951 \\
CAPM+ILLQ alpha & -8.38 & 0.522 & .470 \\
\hline
\end{tabular}

This table reports the differences in percent per year between estimated alphas based on five asset pricing models; CAPM, Fama-French, and three liquidity-based asset pricing model alphas. We form four differently sorted portfolios according to (i) the sensitivities of returns with changes in the relative bid-ask spread (HLS); (ii) the sensitivities of returns to fluctuations in aggregate liquidity, as measured by order flow inducing greater return reversals when liquidity is lower (OFL); (iii) the sensitivity of returns to the monthly average across days of the absolute percentage price change per euro of trading volume (ILLQ); and (iv) market capitalization (MV). HLS1 and OFL1 represent stocks negatively sensitive to market-wide liquidity, ILLQ1 includes stocks negatively sensitive to market-wide illiquidity, and MV1 has small market value stocks. Data are from January 1993 to December 2000.

${ }^{\mathrm{a}}$ In percent per year.

${ }^{\mathrm{b}} \chi^{2}$ test of equality between means.

First of all, and regardless of which model is considered, we do not find significant differences for HLS and size-sorted portfolios. It is relevant to point out that using these portfolios and adding the OFL factor to the CAPM does not seem to have any effect on the results. For example, the differences in alphas between portfolios HLS10 and HLS1 is -1.78 for the CAPM, and -1.74 for the CAPM once the OFL factor has been added to the model. The liquidity-based CAPM, when we use our HLS systematic liquidity factor, has a stronger impact on the result. The alpha is now just -0.02 . In any case, as observed above, none of the differences is significantly different from zero. However, the surprising result is the negative and significant difference between the alphas of the extreme portfolios when we use the ranking based on the OFL factor. This is consistent with the result already reported in Table 3. Stocks very positively sensitive to the OFL factor tend to strongly underperform stocks with negative sensitivity to the OFL factor. Of course, this is very disturbing evidence for the liquidity-based model proposed by $\mathrm{P} \& \mathrm{~S}$.

Regarding the results using the 10 liquidity-based portfolios sorted by betas relative to the ILLQ factor, we find significant evidence of a quite strong liquidity premium. In all models, the premium is highly negative (as expected) and significant. It is quite interesting to note that the premium 
increases (in absolute terms) when the model combining the standard CAPM with the ILLQ factor is used. This liquidity-based model generates very high and negative alphas relative to the ones observed from other models. This result is explained by the extraordinary difference between ILLQ1 and ILLQ10 and, fundamentally, by the negative and positive liquidity beta of ILLQ1 and ILLQ10 respectively. ${ }^{18}$ In the latter portfolio, the effect of positive market and liquidity betas tend to reduce the already small average return, generating a high and negative alpha. In the case of ILLQ1, the negative liquidity beta adds return to the already high average return. In fact, the opposite signs of liquidity betas in the two portfolios account for $74 \%$ of the total negative alpha reported in Table $5 .{ }^{19}$ At the same, it should be recognized that the model needs additional state variables to explain average returns adequately. A dynamic context is probably a reasonable framework. ${ }^{20}$ We may conclude that within a time-series context and, at least, for the ILLQ market-wide liquidity, there seems to be a strong evidence of a liquidity premium in the Spanish Stock Market during the 1990s.

\subsection{Cross-sectional evidence}

We now perform empirical tests for both the conditional and unconditional liquidity-based asset pricing models using the three systematic factors described in the paper.

\subsubsection{General asset pricing framework}

The fundamental equation of asset pricing is usually written as:

$$
E_{t-1}\left[M_{t}\left(1+R_{j t}\right)\right]=1 ; \quad j=1, \ldots, N
$$

where $M_{t}$ is the stochastic discount factor. Let $R_{\mathrm{mt}}$ be the return on the true mean-variance efficient portfolio. Then, we know that the discount factor under the liquidity-based unconditional pricing model is given by:

$$
M_{t}=\delta_{0}+\delta_{1} R_{\mathrm{mt}}+\delta_{2} L_{t}
$$

where $\delta_{0}, \delta_{1}$, and $\delta_{2}$ are three constants, and $L_{t}$ is the replicating liquidity portfolio as given by either HLS, OFL or ILLQ. On the other hand, the conditional version may be written as,

$$
M_{t}=\delta_{0 t-1}+\delta_{1 t-1} R_{\mathrm{mt}}+\delta_{2 t-1} L_{t}
$$

where $\delta_{0 t-1}, \delta_{1 t-1}$, and $\delta_{2 t-1}$ are now allowed to vary over time.

\footnotetext{
18 Thus, assets that belong to ILLQ1 are highly risky assets relative to market-wide liquidity, while stocks in the ILLQ10 portfolio hedge against adverse market-wide liquidity shocks.

19 The total monthly alpha is $-4.5 \%$, while the effect of the opposite sign in liquidity beta is $-3.35 \%$. At the same time, the average returns of market return and the ILLQ factor are positive. Indeed, ILLQ is always positive.

${ }^{20}$ The market beta of portfolio ILLQ1 is not high enough to offset the negative liquidity beta. It works out to 1.31 , but to obtain a zero alpha, its market beta should be as high as 3.6. Thus, market risk is not properly captured just by its market beta in this liquidity-based asset pricing model.
} 
Given that the true conditional distribution is unobservable, we merely assume (as usual in conditional asset pricing literature) a linear relationship between the parameters $\delta_{0 t-1}, \delta_{1 t-1}, \delta_{2 t-1}$ and a time $t-1$ information variable that is a predicting the variable for returns, which, in our case, is given by the (log) aggregate $\mathrm{BM}$ ratio, $\mathrm{bm}_{t-1}$ :

$$
\delta_{i t-1}=\delta_{i}+\delta_{i 1} \mathrm{bm}_{t-1} ; \quad i=0,1,2
$$

where $\delta_{i}$ and $\delta_{i 1}$ are constants. Plugging Eq. (12) into Eq. (11), we transform the conditional liquiditybased asset pricing model into the so-called scaled liquidity-based asset pricing model, ${ }^{21}$ which is simply an unconditional multifactor model with constant coefficients.

The fundamental asset pricing equation is then

$$
E_{t-1}\left\{\left[\delta_{0}+\delta_{01} \mathrm{bm}_{t-1}+\delta_{1} R_{\mathrm{mt}}+\delta_{11}\left(\mathrm{bm}_{t-1} R_{\mathrm{mt}}\right)+\delta_{2} L_{t}+\delta_{21}\left(\mathrm{bm}_{t-1} L_{t}\right)\right]\left(1+R_{j t}\right)\right\}=1
$$

The corresponding beta coefficients are given by

$$
\begin{aligned}
\beta_{j m} & =\frac{\operatorname{cov}\left(R_{j t}, R_{\mathrm{mt}}\right)}{\operatorname{var}\left(R_{\mathrm{mt}}\right)} \\
\beta_{j \mathrm{bm}} & =\frac{\operatorname{cov}\left(R_{j t}, \mathrm{bm}_{t-1}\right)}{\operatorname{var}\left(\mathrm{bm}_{t-1}\right)} \\
\beta_{j m \mathrm{bm}} & =\frac{\operatorname{cov}\left(R_{j t}, \mathrm{bm}_{t-1} R_{\mathrm{mt}}\right)}{\operatorname{var}\left(\mathrm{bm}_{t-1} R_{\mathrm{mt}}\right)} \\
\beta_{j L} & =\frac{\operatorname{cov}\left(R_{j t}, L_{t}\right)}{\operatorname{var}\left(L_{t}\right)} \\
\beta_{j L \mathrm{bm}} & =\frac{\operatorname{cov}\left(R_{j t}, \mathrm{bm}_{t-1} L_{t}\right)}{\operatorname{var}\left(\mathrm{bm}_{t-1} L_{t}\right)} .
\end{aligned}
$$

The asset pricing model (Eq. (13)) can be written in the traditional multibeta representation as

$$
E\left(R_{j}\right)=\gamma_{0}+\gamma_{1} \beta_{j m}+\gamma_{2} \beta_{j \mathrm{bm}}+\gamma_{3} \beta_{j m \mathrm{bm}}+\gamma_{4(6)(8)} \beta_{j L}+\gamma_{5(7)(9)} \beta_{j L \mathrm{bm}}
$$

where $\gamma_{4}$ and $\gamma_{5}$ correspond to HLS, $\gamma_{6}$ and $\gamma_{7}$ to OFL, and $\gamma_{8}$ and $\gamma_{9}$ to ILLQ. This will be the basic model employed in our empirical exercise to test the competing liquidity-based pricing models.

\subsubsection{Empirical evidence}

The results are reported in Table 6 for the four alternative sets of portfolios. In particular, as the dependent variable in the Fama-MacBeth monthly regressions, we employ the 10 portfolios constructed on the basis of sensitivity to market-wide liquidity factors and the traditional 10 size-sorted portfolios. The results are reported in four panels, where Panel A, B, C and D contain the cross-sectional results for the HLS, OFL, ILLQ, and MV sorted portfolios, respectively.

${ }^{21}$ See Cochrane (2001). 
With the key exception of portfolios based on liquidity betas relative to ILLQ, the results for Panels A, B, and D are quite similar, independently of the rest of the endogenous variables used in the test. As expected, the liquidity premium associated with the HLS factor is always positive, but, unfortunately, it is never significantly different from zero. ${ }^{22}$ In principle, the results relative to the OFL factor are even more disappointing because, except for the size-sorted portfolios, the liquidity premium has the wrong sign. This is consistent with the differences in alphas found in Table 5. Despite the success of the P\&S (2003) factor when U.S. market data is employed, ${ }^{23}$ their factor does not seem to be priced in the Spanish market. ${ }^{24}$ Of course, this result must be interpreted with care given the short period of time covered by this research. Unfortunately, the Spanish continuous market did not start trading until 1989. Given the design employed in any asset pricing work, where key parameters are estimated with relatively long series of past data, we are forced to use monthly data only from 1993 to 2000 in our tests of the asset pricing models. This may be considered to be short for a paper of these characteristics. However, as we discuss below, much more favorable evidence is found for the ILLQ factor. Hence, the concern regarding the unusually short sample period is probably not as important as it might initially appear. On other hand, testing a model like the one proposed by P\&S with an alternative database and making comparisons with competing liquidity factors seems to be a crucial step in this type of research.

There are other interesting results in Table 6. When the OFL portfolios are used, the market risk premium becomes positive and significant whenever we add any of the liquidity factors. Interestingly, under these portfolios, the estimate of the market premium in the standard CAPM context is 1.10, with a $t$ value of 0.13 . On the other hand, however, the market risk premium is not different from zero in any other panel. Adding any of the liquidity factors does not affect the market risk premium either with HLS, ILLQ, or size-sorted portfolios.

In terms of the conditional version of the models and for the HLS factor, both the market risk and the liquidity premiums have the correct positive sign, but we can never statistically reject their being zero. The liquidity premium, in all cases, becomes much larger than the one obtained under the unconditional version. However, they are all estimated with too much noise and, consequently, the liquidity premiums are never significantly different from zero. Interestingly, in all panels, the coefficient associated with the instrument is always negative and highly significant. The BM ratio predicts the returns in a positive fashion. Moreover, any increase in BM ratio suggests that market prices go down relatively more than book values do. This fall represents bad news for the market. Hence, assets whose returns covary positively with the (lagged) BM ratio tend to pay when marginal utility is high (financial wealth low), and, therefore, investors should be "willing" to pay to invest in those stocks. This explains the negative sign of the BM beta and points toward a relevant state variable in asset pricing. It should be recalled that the BM ratio plays a similar role with the consumption-wealth ratio of Lettau and Ludvigson (2001) in the U.S. market. ${ }^{25}$

22 The first line in parenthesis is the usual $t$ statistic for the average gamma. The second line is a $t$ statistic, robust to serially correlated monthly gammas. It is calculated by a regression of the monthly gammas of each model on just a constant and employing the consistent Newey-West standard errors of the coefficients with three lags. A number in bold indicates that the coefficient is significantly different from zero.

23 See P\&S and Sadka (2003).

24 The conditional version of the liquidity-based model with the OFL factors obtains different results, as we discuss below.

25 See Nieto and Rodríguez (2002). 
Table 6

Cross-sectional unconditional and conditional asset pricing model tests with portfolios 1993-2000

\begin{tabular}{|c|c|c|c|c|c|c|c|c|c|c|}
\hline$\gamma_{0}$ & $\gamma_{1}$ & $\gamma_{2}$ & $\gamma_{3}$ & $\gamma_{4}$ & $\gamma_{5}$ & $\gamma_{6}$ & $\gamma_{7}$ & $\gamma_{8}$ & $\gamma_{9}$ & $R^{2}$ \\
\hline \multicolumn{11}{|c|}{ (A) 10 HLS portfolios } \\
\hline 0.2288 & 1.0775 & - & - & 0.0448 & - & - & - & - & - & 41.9 \\
\hline$(0.42)$ & $(1.40)$ & & & $(0.12)$ & & & & & & \\
\hline$(0.44)$ & $(1.21)$ & & & $(0.12)$ & & & & & & \\
\hline 0.1607 & 1.1705 & - & - & - & - & -5.258 & - & - & - & 33.4 \\
\hline$(0.24)$ & $(1.30)$ & & & & & $(-1.40)$ & & & & \\
\hline$(0.26)$ & $(1.28)$ & & & & & $(-1.26)$ & & & & \\
\hline 0.7023 & 0.6383 & - & - & - & - & - & - & -0.9577 & - & 35.0 \\
\hline (1.07) & $(0.74)$ & & & & & & & $(-0.29)$ & & \\
\hline$(1.00)$ & $(0.71)$ & & & & & & & $(-0.27)$ & & \\
\hline 1.2778 & 0.1881 & -22.160 & -0.3063 & 0.5895 & 0.1904 & - & - & - & - & 71.1 \\
\hline$(2.02)$ & $(0.22)$ & $(-3.44)$ & $(-0.79)$ & $(1.11)$ & $(0.62)$ & & & & & \\
\hline$(2.16)$ & $(0.22)$ & $(-2.92)$ & $(-0.74)$ & (1.18) & $(0.71)$ & & & & & \\
\hline 1.0058 & 0.3353 & -12.567 & -0.2141 & - & - & -5.5506 & 1.0186 & - & - & 69.7 \\
\hline$(1.65)$ & $(0.38)$ & $(-2.25)$ & $(-0.55)$ & & & $(-1.14)$ & $(0.78)$ & & & \\
\hline$(2.13)$ & $(0.40)$ & $(-2.03)$ & $(-0.53)$ & & & $(-1.53)$ & (1.08) & & & \\
\hline 0.6963 & 0.6696 & -21.9921 & -0.2505 & - & - & - & - & -3.3527 & -3.3271 & 72.5 \\
\hline$(1.04)$ & $(0.69)$ & $(-3.50)$ & $(-0.55)$ & & & & & $(-0.79)$ & $(-2.83)$ & \\
\hline (1.18) & $(0.75)$ & $(-2.94)$ & $(-0.57)$ & & & & & $(-0.62)$ & $(-2.74)$ & \\
\hline \multicolumn{11}{|c|}{ (B) 10 OFL portfolios } \\
\hline-0.8835 & 2.2450 & - & - & 0.2773 & - & - & - & - & - & 31.9 \\
\hline$(-1.18)$ & $(2.21)$ & & & $(0.38)$ & & & & & & \\
\hline$(-1.04)$ & $(1.77)$ & & & $(0.34)$ & & & & & & \\
\hline-0.2216 & 1.5790 & - & - & - & - & -0.8743 & - & - & - & 32.5 \\
\hline$(-0.33)$ & $(1.91)$ & & & & & $(-0.40)$ & & & & \\
\hline$(-0.36)$ & $(1.69)$ & & & & & $(-0.41)$ & & & & \\
\hline-0.3340 & 1.7155 & - & - & - & - & - & - & -1.1684 & - & 31.6 \\
\hline$(-0.45)$ & (1.91) & & & & & & & $(-0.51)$ & & \\
\hline$(-0.58)$ & (1.90) & & & & & & & $(-0.45)$ & & \\
\hline-0.1617 & 1.5408 & -18.444 & 0.0583 & 0.6452 & 0.2385 & - & - & - & - & 69.3 \\
\hline$(-0.16)$ & $(1.32)$ & $(-3.55)$ & $(0.17)$ & $(0.71)$ & $(0.70)$ & & & & & \\
\hline$(-0.16)$ & (1.31) & $(-2.89)$ & $(0.19)$ & $(0.66)$ & $(0.71)$ & & & & & \\
\hline 0.9389 & 0.4688 & -12.302 & -0.2190 & - & - & -1.1319 & -0.1218 & - & - & 70.3 \\
\hline (1.05) & $(0.46)$ & $(-2.45)$ & $(-0.51)$ & & & $(-0.50)$ & $(-0.15)$ & & & \\
\hline (1.49) & $(0.58)$ & $(-2.32)$ & $(-0.64)$ & & & $(-0.57)$ & $(-0.17)$ & & & \\
\hline-0.6263 & 1.9752 & -17.6377 & -0.3550 & - & - & - & - & 2.6719 & -2.6126 & 64.9 \\
\hline$(-0.49)$ & $(1.30)$ & $(-3.46)$ & $(-0.78)$ & & & & & (1.09) & $(-3.08)$ & \\
\hline$(-0.46)$ & (1.10) & $(-3.45)$ & $(-0.63)$ & & & & & $(1.15)$ & $(-2.58)$ & \\
\hline \multicolumn{11}{|c|}{ (C) 10 ILLQ portfolios } \\
\hline 0.1207 & 1.2021 & - & - & 0.6264 & - & - & - & - & - & 34.0 \\
\hline$(0.25)$ & $(1.50)$ & & & $(0.92)$ & & & & & & \\
\hline$(0.18)$ & $(1.10)$ & & & $(0.94)$ & & & & & & \\
\hline 0.1536 & 1.1539 & - & - & - & - & -0.0609 & - & - & - & 34.3 \\
\hline$(0.32)$ & $(1.55)$ & & & & & $(-0.02)$ & & & & \\
\hline$(0.25)$ & (1.13) & & & & & $(-0.03)$ & & & & \\
\hline
\end{tabular}


Table 6 (continued)

\begin{tabular}{|c|c|c|c|c|c|c|c|c|c|c|}
\hline$\underline{\gamma_{0}}$ & $\gamma_{1}$ & $\gamma_{2}$ & $\gamma_{3}$ & $\gamma_{4}$ & $\gamma_{5}$ & $\gamma_{6}$ & $\gamma_{7}$ & $\gamma_{8}$ & $\gamma_{9}$ & $R^{2}$ \\
\hline \multicolumn{11}{|c|}{ (C) 10 ILLQ portfolios } \\
\hline $\begin{array}{l}\mathbf{1 . 8 9 9 4} \\
(3.13) \\
(3.29)\end{array}$ & $\begin{array}{l}-0.5467 \\
(-0.70) \\
(-0.75)\end{array}$ & - & - & - & - & - & - & $\begin{array}{l}-\mathbf{5 . 4 9 7 1} \\
(-2.62) \\
(-1.99)\end{array}$ & - & 39.8 \\
\hline 1.7090 & -0.3346 & -23.3512 & -0.1349 & -0.8311 & 0.9451 & - & - & - & - & 73.5 \\
\hline$(2.13)$ & $(-0.34)$ & $(-4.82)$ & $(-0.35)$ & $(-0.59)$ & $(1.19)$ & & & & & \\
\hline$(1.95)$ & $(-0.34)$ & $(-3.94)$ & $(-0.31)$ & $(-0.60)$ & $(1.25)$ & & & & & \\
\hline 1.7687 & -0.3961 & -16.4454 & -0.0831 & - & - & 6.4186 & -0.3492 & - & - & 69.2 \\
\hline$(3.00)$ & $(-0.53)$ & $(-3.45)$ & $(-0.23)$ & & & $(1.73)$ & $(-0.38)$ & & & \\
\hline$(2.83)$ & $(-0.50)$ & $(-2.55)$ & $(-0.22)$ & & & (1.94) & $(-0.47)$ & & & \\
\hline 1.3765 & -0.0573 & -14.6441 & 0.1153 & - & - & - & - & -4.8825 & -2.3884 & 71.8 \\
\hline (1.96) & $(-0.07)$ & $(-2.61)$ & $(0.33)$ & & & & & $(-2.22)$ & $(-3.39)$ & \\
\hline$(1.75)$ & $(-0.06)$ & $(-2.14)$ & $(0.32)$ & & & & & $(-1.61)$ & $(-3.16)$ & \\
\hline \multicolumn{11}{|c|}{ (D) $10 \mathrm{MV}$ portfolios } \\
\hline 0.5347 & 0.8529 & - & - & 0.4998 & - & - & - & - & - & 43.7 \\
\hline$(0.87)$ & $(1.08)$ & & & $(0.79)$ & & & & & & \\
\hline$(0.90)$ & $(1.06)$ & & & $(0.81)$ & & & & & & \\
\hline 0.9540 & 0.4447 & - & - & - & - & 1.1727 & - & - & - & 40.7 \\
\hline$(1.59)$ & $(0.59)$ & & & & & $(0.42)$ & & & & \\
\hline$(1.54)$ & $(0.53)$ & & & & & $(0.44)$ & & & & \\
\hline 1.2653 & 0.1007 & - & - & - & - & - & - & 0.2700 & - & 35.3 \\
\hline (1.99) & $(0.15)$ & & & & & & & $(0.15)$ & & \\
\hline (2.04) & $(0.14)$ & & & & & & & $(0.16)$ & & \\
\hline 1.3824 & -0.0674 & -16.334 & -0.324 & 0.7414 & 0.1561 & - & - & - & - & 75.8 \\
\hline$(2.08)$ & $(-0.07)$ & $(-3.13)$ & $(-0.99)$ & $(0.95)$ & $(0.59)$ & & & & & \\
\hline$(2.35)$ & $(-0.08)$ & $(-3.37)$ & $(-0.91)$ & $(0.85)$ & $(0.56)$ & & & & & \\
\hline 1.4940 & -0.1376 & -20.645 & -0.4090 & - & - & 3.4146 & 0.1715 & - & - & 72.7 \\
\hline$(2.53)$ & $(-0.15)$ & $(-3.21)$ & $(-1.06)$ & & & $(0.98)$ & $(0.19)$ & & & \\
\hline$(2.41)$ & $(-0.14)$ & $(-2.86)$ & $(-1.06)$ & & & $(1.00)$ & $(0.16)$ & & & \\
\hline 0.0815 & 1.2775 & -9.9836 & -0.1797 & - & - & - & - & 1.4439 & -1.3927 & 72.9 \\
\hline$(0.12)$ & (1.49) & $(-1.77)$ & $(-0.42)$ & & & & & $(0.32)$ & $(-1.80)$ & \\
\hline$(0.12)$ & (1.54) & $(-1.53)$ & $(-0.38)$ & & & & & $(0.30)$ & $(-1.81)$ & \\
\hline
\end{tabular}

This table contains the time series averages of the monthly coefficients in cross-sectional asset pricing tests using standard FamaMacBeth methodology. The dependent variable is the monthly return on four differently sorted portfolios according to (i) the sensitivities of returns with changes in the relative bid-ask spread (HLS); (ii) the sensitivity of returns to fluctuations in aggregate liquidity, as measured by order flow inducing greater return reversals when liquidity is lower (OFL); (iii) the sensitivity of returns to the monthly average across days of the absolute percentage price change per euro of trading volume (ILLQ); (iv) market capitalization (MV) from January 1993 to December 2000. The explanatory variables are the betas of the different factors estimated with the 35 previous monthly returns to each cross-sectional estimation and the corresponding month itself, for a total of 36 observations in each regression. The conditioning variable is the $(\log )$ of the aggregate BM ratio, and the models are three CAPM liquidity-based asset pricing models. In parentheses, we report the Fama-MacBeth $t$ statistic, and in the line below the $t$ statistic, robust to serially correlated gammas. Items in bold are statistically different from zero. The cross-sectional regressions for each month take the following form:

$$
R_{j}=\gamma_{0}+\gamma_{1} \beta_{j m}+\gamma_{2} \beta_{j \mathrm{bm}}+\gamma_{3} \beta_{j m \mathrm{bm}}+\gamma_{4} \beta_{j \mathrm{HLS}}+\gamma_{5} \beta_{j \mathrm{HLSbm}}+\gamma_{6} \beta_{j \mathrm{OFL}}+\gamma_{7} \beta_{j \mathrm{OFLbm}}+\gamma_{8} \beta_{j \mathrm{LLLQ}}+\gamma_{9} \beta_{j \mathrm{ILLQbm}}+\eta_{j} .
$$


Finally, the most interesting results of Table 6 are contained in Panel C, where assets are classified according to the sensitivity to ILLQ. Despite the large differences in average returns between the 10 portfolios, the liquidity premium associated with either HLS or OFL in the unconditional versions is not significantly different from zero. The coefficient of betas relative to HLS, at least, has the expected sign and is positive. The significant and positive liquidity premium relative to the OFL factor when the conditional model is employed should be noted. This is consistent with the importance of adding dynamics in the asset pricing models when Spanish data are used. This result, to some extent, conciliates the results found in the U.S. market with those in Spain and points out the lack of robustness of asset pricing model tests to alternative portfolio formation.

The key result of the paper is the significant negative coefficients of the betas relative to ILLQ in both the unconditional and conditional versions of the liquidity-based asset pricing models. Note that when there is an adverse market-wide liquidity shock, ILLQ increases. Then, assets that pay lower returns in those liquidity restriction periods (negative liquidity betas) will be required to offer an extra return. Therefore, the gamma coefficient associated with the liquidity (ILLQ) beta should be negative for the results to be consistent with a liquidity risk premium. Panel $\mathrm{C}$ shows that this is indeed the case. As before, there is also a negative sign associated with the BM beta and the cross-product term, but the liquidity risk premium remains significant. Hence, under a dynamic asset pricing, aggregate liquidity also seems to be a risk factor priced by the market. To conclude, the dispersal of average returns in these portfolios and the relevant measure of the market-wide illiquidity lead towards a significant liquidity risk premium in the Spanish market.

\subsubsection{Some additional empirical evidence}

As discussed in the Introduction, most of the papers analyzing the influence of liquidity on asset pricing use the level of liquidity to investigate the possibility of a premium. The argument is that stocks with low liquidity should earn a higher expected return. This strategy of testing asset pricing with the liquidity costs measured in levels lies outside the framework of this paper. However, the earlier evidence on this issue of Amihud and Mendelson (1986) and others, and the recent finding of Acharya and Pedersen (2003), who find a significant relation between a stock's illiquidity and returns, have led us to perform a cross-sectional test in which we include the average relative bid-ask spread of each of the 10 liquidity-based portfolios as an explanatory variable. The results for the set of portfolios based on ILLQ are contained in Table 7. As it turns out, the coefficient associated with the relative bid-ask spread is significant, but it presents the wrong sign. This disturbing finding for an asset pricing model, based on liquidity as a characteristic, has also been reported by Brennan and Subrahmanyam (1996) and Eleswarapu and Reinganum (1993), using U.S. data, and by Rubio and Tapia (1998) with Spanish data. These papers show a strong seasonal and positive January effect on the coefficient of the relative bid-ask spread. However, for all months, the average coefficient tends to be negative and significant. When we use the liquidity beta on the regression, we again find a liquidity risk premium despite the fact that we keep the relative bid-ask spread in the regression. The level of liquidity does not seem to be the relevant variable in asset pricing; rather, the sensitivity of the returns to market-wide liquidity risk factor is what is priced by the market.

Finally, given the lack of robustness of our empirical results, we perform the cross-sectional test using individual assets instead of portfolios. To mitigate the errors-in-variable problem associated with individual betas, we estimate the market model with the ILLQ liquidity factor for each month in the sample using the past 35 months and the month itself, and for each of the 10 liquidity-based 
Table 7

Cross-sectional unconditional asset pricing model tests with portfolios and the relative bid-ask spread as characteristic 19932000

10 ILLQ portfolios

\begin{tabular}{llll}
\hline$\gamma_{0}$ & $\gamma_{1}$ & $\gamma_{8}$ & $\gamma_{10}$ \\
\hline 0.6387 & 1.2479 & - & $-\mathbf{6 9 . 7 5 4}$ \\
$(1.10)$ & $(1.56)$ & & $(-1.67)$ \\
$(0.86)$ & $(1.12)$ & & $(-1.31)$ \\
$\mathbf{2 . 2 5 8 5}$ & -0.4191 & $-\mathbf{5 . 6 1 2 7}$ & $-\mathbf{5 8 . 5 4 9}$ \\
$(3.30)$ & $(-0.50)$ & $(-2.61)$ & $(-1.69)$ \\
$(3.43)$ & $(-0.52)$ & $(-2.09)$ & $(-1.51)$ \\
\hline
\end{tabular}

This table contains the time series averages of the monthly coefficients in cross-sectional asset pricing tests using the standard FamaMacBeth methodology. The dependent variable is the monthly return on 10 sorted portfolios by the sensitivity of returns to the monthly average across days of the absolute percentage price change per euro of trading volume (ILLQ). Data are from January 1993 to December 2000. The models are the illiquidity-based asset pricing model, and the model with the relative spread as characteristic $\left(\mathrm{SP}_{j}\right)$. In parentheses, we report the Fama-MacBeth $t$ statistic, and in the line below, the $t$ statistic robust to serially correlated gammas. Items in bold are statistically different from zero. The cross-sectional regressions for each month take the following form:

$$
R_{j}=\gamma_{0}+\gamma_{1} \beta_{j m}+\gamma_{8} \beta_{j \mathrm{ILLQ}}+\gamma_{10} \mathrm{SP}_{j}+\eta_{j} \text {. }
$$

Table 8

Cross-sectional unconditional asset pricing model tests with individual assets 1993-2000

\begin{tabular}{|c|c|c|c|c|c|c|c|c|c|c|}
\hline$\gamma_{0}$ & $\gamma_{1}$ & $\gamma_{2}$ & $\gamma_{3}$ & $\gamma_{4}$ & $\gamma_{5}$ & $\gamma_{6}$ & $\gamma_{7}$ & $\gamma_{8}$ & $\gamma_{9}$ & $R^{2}$ \\
\hline \multicolumn{11}{|c|}{ (A) Individual stock returns and the equally weighted market return } \\
\hline 0.5232 & 0.8167 & \multirow[t]{3}{*}{-} & \multirow[t]{3}{*}{-} & -0.1761 & \multirow[t]{3}{*}{-} & \multirow[t]{3}{*}{-} & \multirow[t]{3}{*}{-} & \multirow[t]{3}{*}{-} & \multirow[t]{3}{*}{-} & \multirow[t]{3}{*}{16.8} \\
\hline$(1.58)$ & $(1.17)$ & & & $(-0.47)$ & & & & & & \\
\hline (1.69) & $(1.07)$ & & & $(-0.43)$ & & & & & & \\
\hline 0.4686 & 0.8559 & \multirow[t]{3}{*}{-} & \multirow[t]{3}{*}{-} & \multirow[t]{3}{*}{-} & \multirow[t]{3}{*}{-} & \multirow{3}{*}{$\begin{array}{l}-2.5543 \\
(-1.55) \\
(-1.37)\end{array}$} & \multirow[t]{3}{*}{-} & \multirow[t]{3}{*}{-} & \multirow[t]{3}{*}{-} & \multirow[t]{3}{*}{15.2} \\
\hline$(1.28)$ & $(1.23)$ & & & & & & & & & \\
\hline$(1.41)$ & $(1.18)$ & & & & & & & & & \\
\hline 0.9299 & 0.4519 & \multirow[t]{3}{*}{-} & \multirow[t]{3}{*}{-} & \multirow[t]{3}{*}{-} & \multirow[t]{3}{*}{-} & \multirow[t]{3}{*}{-} & \multirow[t]{3}{*}{-} & -3.1207 & \multirow[t]{3}{*}{-} & \multirow[t]{3}{*}{13.8} \\
\hline$(2.38)$ & $(0.65)$ & & & & & & & $(-2.04)$ & & \\
\hline$(2.88)$ & $(0.69)$ & & & & & & & $(-1.55)$ & & \\
\hline 0.8783 & 0.5349 & \multirow[t]{3}{*}{-} & \multirow[t]{3}{*}{-} & -0.1529 & \multirow[t]{3}{*}{-} & -1.4652 & \multirow[t]{3}{*}{-} & -3.5543 & \multirow[t]{3}{*}{-} & \multirow[t]{3}{*}{69.2} \\
\hline (2.59) & $(0.78)$ & & & $(-0.40)$ & & $(-0.91)$ & & $(-2.26)$ & & \\
\hline$(3.20)$ & $(0.78)$ & & & $(-0.36)$ & & $(-0.90)$ & & $(-1.65)$ & & \\
\hline \multicolumn{11}{|c|}{ (B) Individual stock returns and the value-weighted market return } \\
\hline 1.0447 & 0.2098 & \multirow[t]{3}{*}{-} & \multirow[t]{3}{*}{-} & - & - & - & - & -3.3936 & - & 13.1 \\
\hline (2.69) & $(0.29)$ & & & & & & & $(-2.06)$ & & \\
\hline$(2.62)$ & $(0.37)$ & & & & & & & $(-1.47)$ & & \\
\hline
\end{tabular}

This table contains the time series averages of the monthly coefficients in cross-sectional asset pricing tests using the standard FamaMacBeth methodology. The dependent variable is the monthly return of individual stock returns available during the sample period. Data are from January 1993 to December 2000. The explanatory variables are the betas of the different portfolios to which the individual assets belong to in every month during the period. The models are three CAPM liquidity-based asset pricing models. In parentheses, we report the Fama-MacBeth $t$ statistic, and in the line below, the $t$ statistic robust to serially correlated gammas. Items in bold are statistically different from zero. The cross-sectional regressions for each month take the following form:

$$
R_{j}=\gamma_{0}+\gamma_{1} \beta_{j m}+\gamma_{2} \beta_{j \mathrm{bm}}+\gamma_{3} \beta_{j m \mathrm{bm}}+\gamma_{4} \beta_{j \mathrm{HLS}}+\gamma_{5} \beta_{j \mathrm{HLSbm}}+\gamma_{6} \beta_{j \mathrm{OFL}}+\gamma_{7} \beta_{j \mathrm{OFLbm}}+\gamma_{8} \beta_{j \mathrm{ILLQ}}+\gamma_{9} \beta_{j \mathrm{ILLQbm}}+\eta_{j} .
$$


portfolios. We then have a rolling beta for each of the 10 portfolios. The market and liquidity betas of each company in the cross-section are the betas of the portfolio in which the particular stock is located. ${ }^{26}$ Given these explanatory variables, we perform the Fama-MacBeth regression with both the equally weighted and value-weighted market returns. The results for the unconditional asset pricing models are reported in Table 8. Again, as with the 10 portfolios formed on the basis of sensitivities to ILLQ, we find a significant liquidity risk premium. Moreover, regardless of whether only betas relative to ILLQ or betas with respect to all market-wide liquidity measures simultaneously are used, the only significant coefficient is the one related to ILLQ. This makes us more confident in regard to the results reported previously with portfolios. Lastly, the results are the same with both the equally and value-weighted market portfolios.

\section{Conclusions}

Market-wide liquidity should be a key ingredient of asset pricing models. If macroeconomic variables anticipate economic recessions, they may also anticipate lower aggregate liquidity. Indeed, the surprising success of the Fama-French HML risk factor may be explained by a state variable closely related to systematic liquidity. The HML factor is usually associated with a distress factor not theoretically identified. Taking into account not only that risky assets offset the beta risk but also the fact that they have a particularly poor performance in recession, it seems plausible to think of systematic liquidity as the missing factor. This paper presents evidence showing that a liquidity risk factor plays a relevant role in explaining the cross-section of average returns in Spain. Regardless of whether an unconditional or a conditional framework is used with the aggregate BM ratio as the state variable, we show that a liquidity risk premium exists in the Spanish market. These results support the recent evidence found with U.S. market data, although they suggest the importance of capturing adequately market-wide liquidity. A simple measure, such as the ratio of absolute return to euro trading volume, seems to be a very reasonable way of capturing the liquidity risk factor. Moreover, this is important because it facilitates further research in the relation between asset pricing and microstructure, given that it becomes possible to avoid detailed microstructure data not always available for long enough sample periods.

\section{Acknowledgements}

Miguel A. Martínez and Gonzalo Rubio acknowledge the financial support provided by Ministerio de Ciencia y Tecnología grant BEC2001-0636. Belén Nieto and Mikel Tapia acknowledge research support from Ministerio de Ciencia y Tecnología grants BEC2002-03797 and BEC2002-00279, respectively. Helpful comments from an anonymous referee substantially improved the paper. All errors are our own.

\footnotetext{
26 The same procedure is employed by running just one regression for the whole sample period for each of the 10 liquiditybased portfolios. The results are very similar with the ones reported in Table 8 .
} 


\section{References}

Acharya, V., \& Pedersen, L. (2003). Asset pricing with liquidity risk. Working Paper, London Business School.

Amihud, Y. (2002). Illiquidity and stock returns: Cross-section and time-series effects. Journal of Financial Markets, 5, 31-56.

Amihud, Y., \& Mendelson, H. (1986). Asset pricing and the bid-ask spread. Journal of Financial Economics, 17, $223-249$.

Brennan, M., \& Subrahmanyam, M. (1996). Market microstructure and asset pricing: On the compensation for illiquidity in stock returns. Journal of Financial Economics, 41, 441-464.

Campbell, J. (2001). Asset pricing at the millennium. Journal of Finance, 55, 1515-1567.

Chordia, T., Roll, R., \& Subrahamanyam, A. (2000). Commonality in liquidity. Journal of Financial Economics, 56, 3-28.

Cochrane, J. (2001). Asset pricing. Princeton, NJ: Princeton University Press.

Constantinides, G. (2002). Rational asset prices. Journal of Finance, 57, 1567-1591.

Domowitz, I., \& Wang, X. (2002). Liquidity, liquidity commonality and its impact on portfolio theory. Working Paper, Penn State University.

Easley, D., Hvidkjaer, S., \& O’Hara, M. (2002). Is information risk a determinants of asset returns? Journal of Finance, 58, $2185-2210$.

Eleswarapu, V., \& Reinganum, M. (1993). The seasonal behavior of liquidity premium in asset pricing. Journal of Financial Economics, 34, 373-386.

Ericsson, J., \& Renault, O. (2000). Liquidity and credit risk. Working Paper, McGill University, Montreal.

Fama, E., \& French, K. (1993). Common risk factors in the returns on stocks and bonds. Journal of Financial Economics, 33, $3-56$.

Forner, C., \& Marhuenda, J. (2003). Contrarian and momentum strategies in the Spanish stock market. European Financial Management Journal, 9, 67-88.

Hasbrouck, J. (2002). Inferring trading costs from daily data: US equities from 1962 to 2001. Working Paper, Stern School of Business, New York University.

Hasbrouck, J., \& Seppi, D. (2001). Common factors in prices, order flows, and liquidity. Journal of Financial Economics, 59, $383-411$.

Holmström, B., \& Tirole, J. (2001). LAPM: A liquidity-based asset pricing. Journal of Finance, 56, 1837-1867.

Huberman, G., \& Halka, D. (1999). Systematic liquidity. Working Paper. Columbia Business School.

Lettau, M., \& Ludvigson, S. (2001). Consumption, aggregate wealth, and expected stock returns. Journal of Finance, 56, $815-849$.

Lustig, H. (2001). The market price of aggregate risk and the wealth distribution. Working Paper, Stanford University.

Martínez, M., Rubio, G., \& Tapia, M. (2003). Understanding the ex-ante cost of liquidity in the limit order book: A note, forthcoming in the Revista de Economía Aplicada.

Nieto, B. (2002). La Valoración Intertemporal de Activos: Un Análisis Empírico para el Mercado Español de Valores. Investigaciones Económicas, 26, 497-524.

Nieto, B., \& Rodríguez, R. (2002). The consumption-wealth and book-to-market ratios in a dynamic asset pricing context. Working Paper, WP-EC 2002-24, Instituto Valenciano de Investigaciones Económicas (IVIE).

Nieto, B., \& Rodríguez, R. (2003). Los Modelos de Valoración de Activos Condicionales: Un Panorama Comparativo Ilustrado con Datos Españoles. Working Paper, Universidad de Alicante.

Pastor, L., \& Stambaugh, R. (2003). Liquidity risk and expected stock returns. Journal of Political Economy, 111, $642-685$.

Rubio, G. (1988). Further international evidence on asset pricing: The case of the Spanish capital market. Journal of Banking and Finance, 12, 221-242.

Rubio, G. (1990). The stock market in Spain: Performance, structure, and the behavior of asset prices. Journal of Financial Markets and Portfolio Management, 4, 332-354.

Rubio, G. (1995). Further evidence on performance evaluation: Portfolio holdings, recommendations, and turnover costs. Review of Quantitative Finance and Accounting, 5, 127-153.

Rubio, G., \& Tapia, M. (1996). Adverse selection, volume, and transactions around dividend announcements in a continuous auction system. European Financial Management Journal, 2, 127-153.

Rubio, G., \& Tapia, M. (1998). The liquidity premium in equity pricing under a continuous auction system. European Journal of Finance, 4, 1-28.

Sadka, R. (2003). Liquidity risk and asset pricing. Working Paper, Kellog School of Management, Northwestern University. 